\title{
La necrópolis saíta de Oxirrinco
}

\author{
Núria CASTELLANO i SOLÉ
}

\begin{abstract}
La ciudad grecorromana de Oxirrinco, que corresponde a la faraónica Pemdye, cuenta con una importante necrópolis, la Necrópolis Alta, con una ocupación desde época faraónica hasta época bizantina. La mayor parte de las tumbas corresponden a la época saíta, con una tipología muy variada: desde estructuras muy sencillas con un pozo que conduce a la cámara sepulcral, hasta plantas complejas en forma radial o con salas adosadas. Hasta el momento se han desenterrado cinco tumbas correspondientes a esta época, algunas en proceso de excavación. La más significativa es la tumba número 1, con siete salas abovedadas y una cámara decorada y con inscripciones jeroglíficas. El estudio de las tumbas nos ha permitido conocer su proceso de construcción y sus características técnicas, así como relacionarlas con el Osireion de Oxirrinco.

\section{Oxyrhynchus Saite necropolis}

The Graecoroman city of Oxyrhynchus, named Pemdje in Pharaonic times, has an important necropolis, the Upper Necropolis, which was in use from the Pharaonic era until the Byzantine period. It contains tombs dating from the Saite, Roman and Coptic period, most displaying a varied typology, from simple structures with a shaft which leads to the burial chamber to those with a complex ground plan showing radial form or with side chambers. At least five of the tombs excavated to date are the Saite Period. Tomb number 1 is the most remarkable example of a shaft tomb, with seven vaulted chambers, one of them decorated with hieroglyphic inscriptions. The study of these tombs, has enabled us to understand the construction process and its technical features, as well as how to relate them to the Osireion of Oxyrhynchus.
\end{abstract}

KEY wORDs: Oxyrhynchus, Saite Period, necropole, Osireion

$\mathrm{E}^{1}$ yacimiento arqueológico de la ciudad grecorromana de Oxirrinco, que sucedió a la faraónica Pemdye, está al lado del pueblo moderno de El-Bahnasa, en la provincia de Minia, y se encuentra a unos $190 \mathrm{~km}$ al sur de El Cairo, en la orilla izquierda del Bahr Yussef. Per-Medyed, que significa "la casa del encuentro", es conocida por las listas geográficas desde la antigüedad faraónica.

Debido a su localización cerca del río, Oxirrinco, capital del nomo XIX del Alto Egipto, gozó de un emplazamiento privilegiado que otorgó gran relevancia a esta ciudad. Además, su posición en relación con la red viaria hacia los oasis del de- sierto occidental hizo que los faraones Apries y Amasis otorgaran a la ciudad una concesión de explotación del comercio de los oasis del norte. Oxirrinco se convirtió entonces en un centro de tráfico caravanero donde se cambiaban productos de África Central, los oasis, Libia y el Mediterráneo. Fruto de esta actividad comercial fue el desarrollo urbanístico de Pemdye a partir de la dinastía XXVI y la presencia de grandes tumbas de funcionarios en este emplazamiento.

Las primeras noticias de época moderna que tenemos de Oxirrinco nos llegan a raíz de la expedición de Napoleón Bonaparte. Vivant Denon visitó la zona y publicó algunos grabados que 


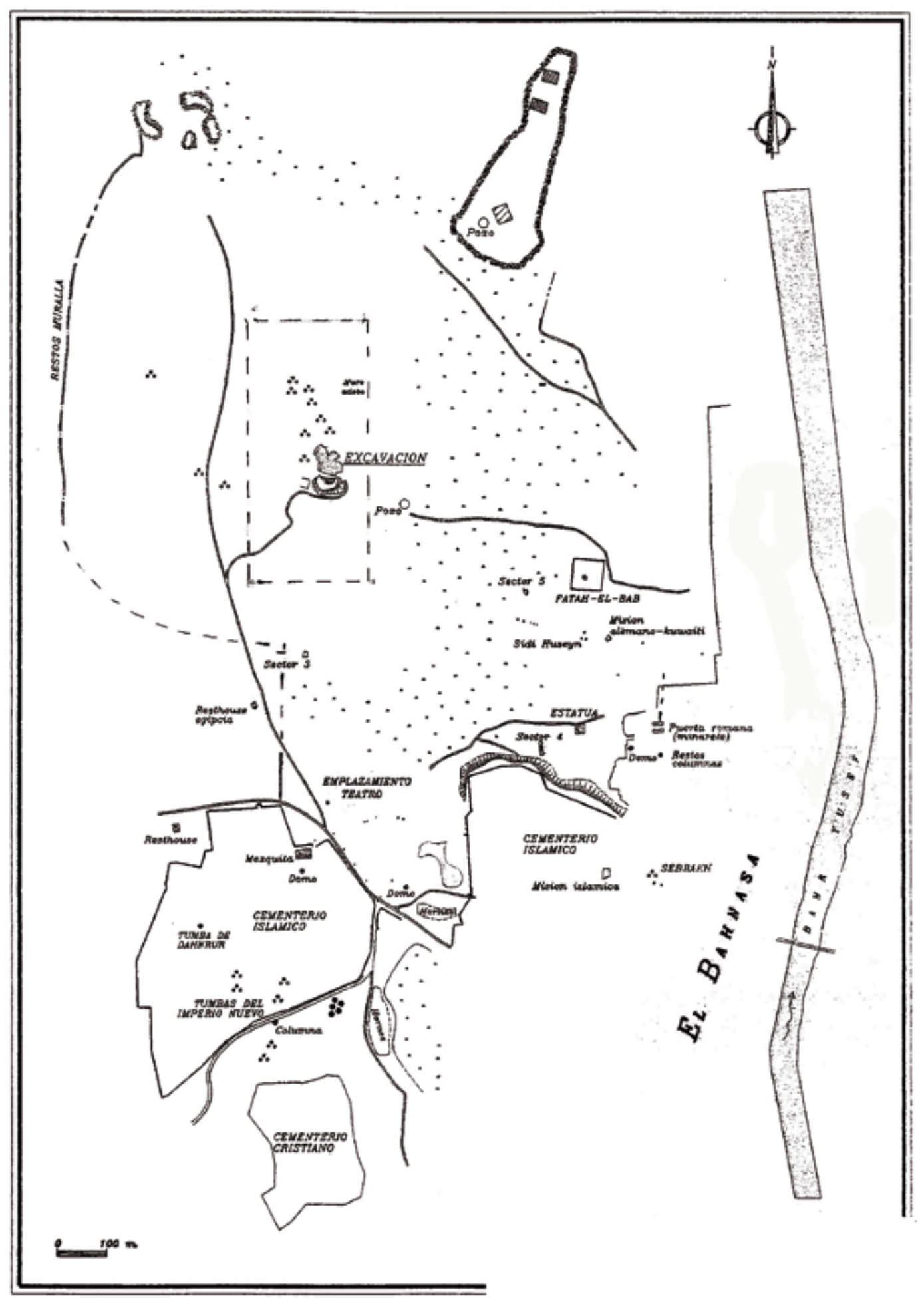

Figura 1. Mapa del yacimiento de Oxirrinco 
constituyen los primeros dibujos de arquitectura antigua conocidos de Oxirrinco. En concreto se trata de una gran columna (actualmente sólo se conserva la parte baja de la que V. Denon dibujó) dedicada al emperador del Imperio de Oriente, Focas.

El estudio arqueológico del yacimiento comenzó con las excavaciones de los papirólogos británicos Bernard Grenfell y Arthur Hunt entre 1897 y 1907, que realizaron un plano muy esquemático del yacimiento. En él localizaron tumbas del Imperio Nuevo y de épocas ptolemaica y romana. Después realizaron campañas de excavación los italianos, entre 1909 y 1914, dirigidas por Hermenegildo Pistelli. Posteriormente, el yacimiento se vio afectado por la construcción de una línea férrea durante la guerra de 1914-18, que tuvo como consecuencia el saqueo acelerado del yacimiento, ya que se aprovechó para extraer sebakh en grandes cantidades.

Flinders Petrie realizó una campaña en 1922 y situó en el plano una columnata, una base de columna honoraria y las ruinas de un teatro y excavó algunas tumbas y capillas funerarias. El Museo Grecorromano de Alejandría también trabajó en Oxirrinco de la mano de Evaristo Breccia en 1927 y 1932. Sus trabajos se centraron en un edificio de época cristiana de piedra, y en la localización de esculturas. Posteriormente se realizaron diferentes intervenciones de urgencia por parte del Servicio de Antigüedades Egipcias.

Pero los resultados más significativos antes de nuestra llegada provienen de las excavaciones del Consejo Supremo de Antigüedades egipcio, dirigidas desde 1982 hasta 1992 por Mahmud
Hamzah. El trabajo arqueológico por parte de esta organización comenzó cuando se descubrió que se estaba saqueando una necrópolis faraónica. La Necrópolis Alta está situada al noroeste de la antigua ciudad fuera de sus límites y en un lugar elevado, cosa que la hace visible aún en la actualidad. Es precisamente la situación cerca del desierto, y el hecho de no estar cubierta de sebakh, lo que ha permitido que se conserve en buenas condiciones. Contiene tumbas que datan, como mínimo, de época saíta, romana y copta, así como una casa funeraria bizantina con importantes pinturas murales.

En 1992, se constituyó una Misión Mixta para excavar el yacimiento, que continúa trabajando en la actualidad ${ }^{1}$.

\section{LA NECRÓPOLIS ALTA}

El nivel del suelo actual es equivalente, en la mayor parte del territorio de la ciudad grecorromana, al del inicio de los cimientos y, por tanto, la humedad y el ascenso de la capa freática hace imposible la recuperación de una completa estratigrafía del lugar. No obstante, en la Necrópolis Alta, la excavación de los diferentes estratos nos permite conocer la evolución del yacimiento desde época saíta, pudiendo establecer tres niveles:

El primero es el superficial y se remonta al período bizantino. Está compuesto por construcciones de adobe: edificaciones, cuyos vestigios no se han podido conservar y por tumbas con una superestructura que formaban parte de una necrópolis bizantina cristiana.

1. La misión española está integrada por el Dr. J. Padró (director de la misión), Dra. E. Subías (responsable de las excavaciones grecorromanas y bizantinas), Dr. H. I. Amer (profesor de la Universidad de El Cairo), Dra. M. ErrouxMorfin (Université Paul Valéry de Montpellier), Dra. E. Pons (Museo Arqueológico Nacional), M.T. Mascort (Generalitat de Catalunya), Dra. N. Castellano (Universitat de Barcelona), N. Rodríguez (arqueóloga), Dra. Ma . L. Mangado (egiptóloga), J. J. Martínez (arqueólogo), R. Xarrié (restaurador), T. López (topógrafo). 
El segundo contiene construcciones del mismo material con techo de bóveda y tumbas comunes del Bajo Imperio romano con pavimento hecho de piedra. En algunas zonas no se conservan edificaciones funerarias sino que sólo se encontraron esqueletos. En otras, se localizaron sarcófagos antropomorfos de piedra con inhumaciones.

El tercero corresponde a una necrópolis de época faraónica construida con piedra caliza, entre 7 y $9 \mathrm{~m}$ de profundidad. De las tumbas descubiertas hasta la actualidad, como mínimo cuatro de ellas corresponden a época saíta, y presentan diversas estructuras subterráneas monumentales con plantas muy diversas.

\section{Tumba $\mathbf{n}^{0} 1$}

Es uno de los vestigios materiales más antiguos de la zona y señala los primeros momentos de ocupación en la Necrópolis Alta. Los trabajos arqueológicos llevados a cabo permitieron descubrir un complejo funerario familiar consistente en siete cámaras con techo de bóveda que alojan sarcófagos para enterramientos del promotor de la tumba y sus parientes. El acceso al subterráneo se efectúa mediante un pozo construido, de planta más o menos cuadrada; el pavimento de losas de piedra está removido. Al final de los 4,20 $\mathrm{m}$ de profundidad del pozo y en los laterales este y oeste, hay dos grafitos de color rojo:

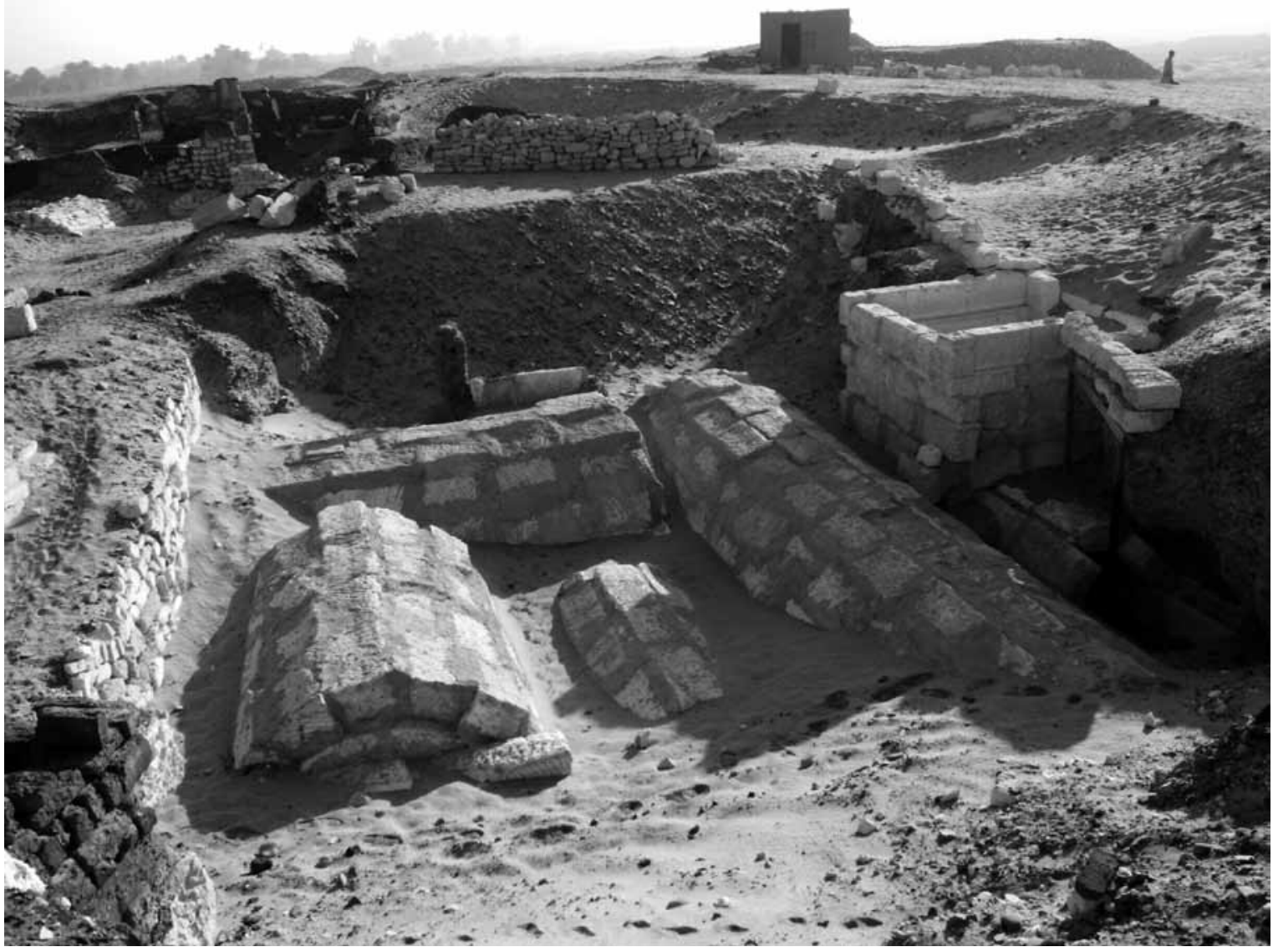

Figura 2. Vista general de la tumba $n^{\circ} 1$ 
el de la derecha está en demótico y habla de un visitante de época de Cleopatra, probablemente Cleopatra VII.

Una puerta situada al norte da paso a la sala 1, la más larga, con 9,62 m de longitud. El suelo de esta estancia, orientada E-W, ha desaparecido en buena parte. Aquí hay dos entradas: una oriental, y otra occidental, que conducen respectivamente a las salas 2 y 5 .

La cámara 2 es la más alta, con 2,70 m de altura. La orientación es N-S y la mitad del pavimento no se conserva. Dos entradas en la pared occidental conducen a las salas 3 y 4 ; en el dintel de la puerta de la primera hay un grafito rojo en jeroglífico cursivo y en demótico. En la primera línea se menciona el nombre de Padineit, pudiéndose tratar del posterior ocupante de esta cámara. La parte en demótico es una advertencia para los visitantes y los posibles ladrones.

La sala 3 es la más importante de todo el complejo funerario, ya que fue donde se enterró el constructor de la tumba. El suelo está a nivel más bajo que el pavimento de la sepultura, orientada E-W y con acceso por el este. Se construyó una fosa excavada con la misma orientación que la cámara, que posiblemente estaba disimulada con losas de piedra. Por encima de ella se encuentra la caja de un sarcófago de piedra caliza que no debía pertenecer al usuario principal, sino que es una muestra de la reutilización de la tumba.

Se puede observar en el interior de la fosa unos pequeños nichos que se construyeron en los laterales de los lados largos para contener los vasos canopos y otro detrás de la cabeza, posiblemente para los ushebtis. Desgraciadamente, el hecho de ser una sepultura violada no nos permite asegurar este hecho, pero la comparación con otras de esta época nos permite establecer esta hipótesis.
La fosa contiene un sarcófago antropomorfo de granito gris de grano fino. Está decorado con inscripciones jeroglíficas, que proporcionaron el nombre del promotor de esta construcción, llamado Het, sacerdote, noble y príncipe, hijo de la dama Tasheritjonsu. Además de los textos jeroglíficos, el sarcófago presenta decoración relacionada con las divinidades funerarias. $\mathrm{La}$ zona pectoral se decoró con un usej con dos cabezas de halcón a la altura del hombro. En el centro, debajo del collar, aparece la diosa Nut con el disco solar y los brazos alados abiertos en un gesto de protección. Se debe destacar que en las manos sujetan plumas de Maat, detalle que era frecuente en sarcófagos de épocas pasadas. Debajo de la diosa hay cinco columnas de textos jeroglíficos, algunos de ellos extraídos de los Textos de las Pirámides. Al final de algunas de las columnas está representada la divinidad a la que se refiere la fórmula. Los Hijos de Horus se muestran con forma humana: Amset y Duamutef a la derecha y Qebsenuf y Hapi a la izquierda. Al lado de ellos se observa el difunto arrodillado delante de Ptah-Tenen a la derecha y Nehebka (agatosdaimon del nomos XIX) a la izquierda. En el empeine se representó a la leona Menet, señora del Abatón y la serpiente Nebneru, como genios vigilantes de las puertas que ayudaban al difunto en el Otro Mundo. En la cabeza del sarcófago la diosa Neftis con los brazos extendidos y con alas protege al difunto, asiendo el signo sa y en los pies aparece Isis con el anj.

El sarcófago de Het es otro elemento que nos permite datar la tumba en época saíta, ya que presenta los rasgos estilísticos típicos de la dinastía XXVI. Se representa al difunto momiforme, con una peluca con estrías verticales que reposan sobre el pecho, dividida en dos bandas verticales. El rostro es una imagen idealizada, con la línea de cosmético marcada, la ceja en relieve y la nariz alar- 


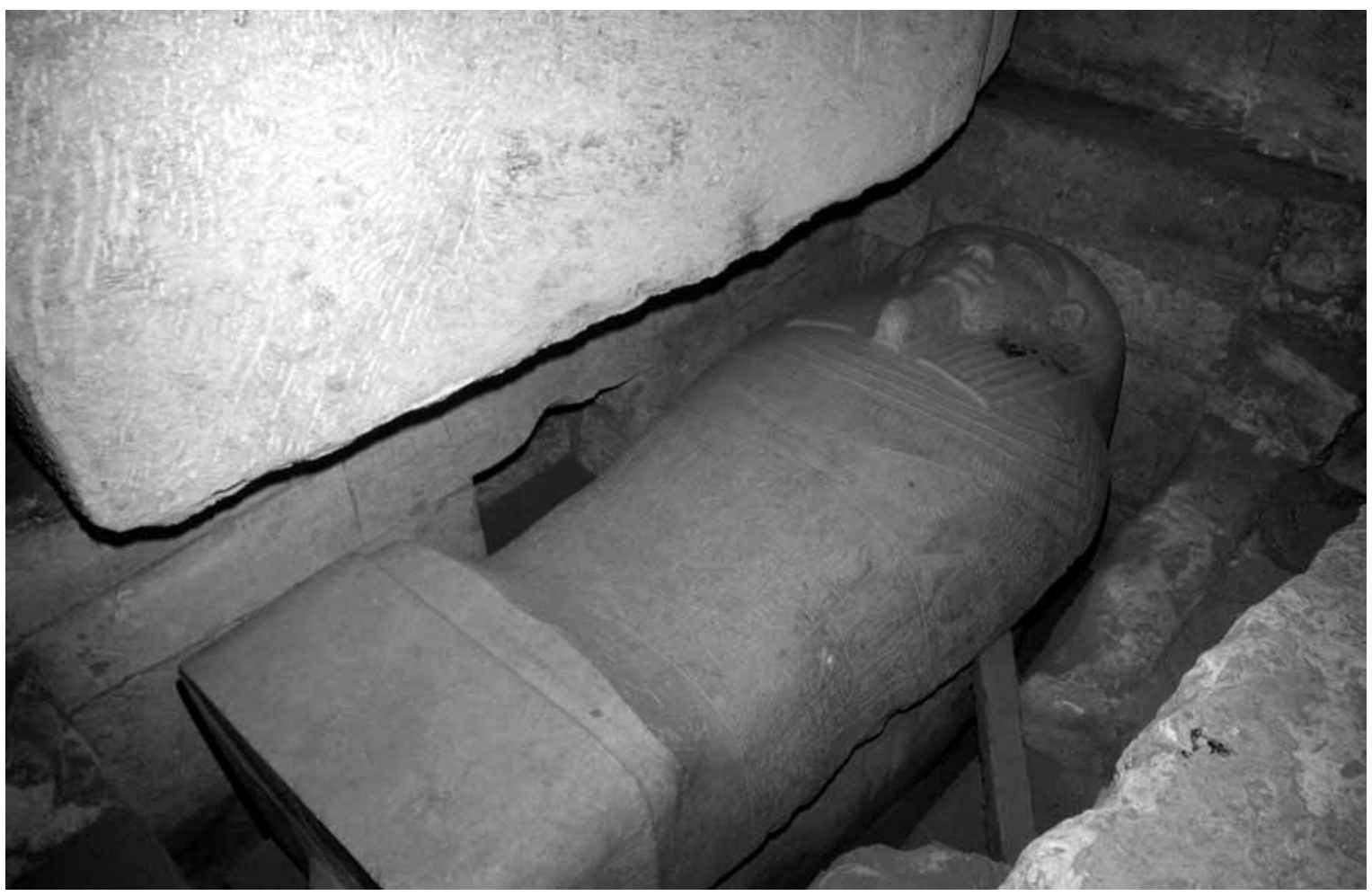

Figura 3. Sarcófago de Het situado en la sala 3 de la tumba $n^{\circ} 1$

gada. La boca es estrecha, con labios carnosos y con una semi-sonrisa, debajo de la cual aparece una barba trenzada y curvada en la punta.

Las inscripciones parietales pintadas en la cámara del sarcófago están mal conservadas, pero en la pared oeste hemos podido localizar el nombre de la ciudad, Per-Medyed y el nombre y títulos del personaje. La decoración del techo de este ámbito consiste en un firmamento azul con estrellas, en el cual se aprecia un agujero de saqueo de la tumba.

Desde la sala 2 también se accede a la sala 4, la cámara situada más al norte y que es la única que tiene el pavimento completo. En la actualidad contiene fragmentos de diversos sarcófagos que se depositaron en la tumba.

La abertura occidental de la sala 1 conduce hasta la cámara 5, donde el pavimento ha desaparecido. Desde ésta, orientada N-S, hay dos accesos a la sala 6 (orientada E-W) y a la sala 7 (orientada N-S). Sobre el dintel de acceso a esta última hay un grafito de color negro con un ojo udyat. Contiene dos sarcófagos de piedra, uno en un estado de conservación muy lamentable y el otro con una inscripción jeroglífica que nos ha permitido datar "ante quem" la época de construcción de la tumba. Tenía en la tapa un cartucho, dentro del cual aparecía el nombre de Uahibre. Durante el Imperio Antiguo, era costumbre que algunos altos funcionarios pudieran adoptar como nombre suyo, uno de los nombres que formaban parte del protocolo faraónico del rey al cual servían. Este título, que se llamaba $r n$ nfr, reaparece en esta época. Además es costumbre que a partir de época del faraón Apries, los altos 
funcionarios puedan, incluso, encerrar su nombre en un cartucho. Tal es el caso del sarcófago localizado en la sala 7 de la tumba 1, donde figura pintado en un cartucho el nombre Uahibre, rn nfr del faraón Apries².

Posteriormente, se añadió una pequeña cámara al sur de la sepultura, adosada al pozo de entrada. Está cubierta con una bóveda poligonal y no se ha recuperado ningún sarcófago en su interior.

Al norte de esta gran estructura funeraria se observó un gran recorte en la roca y en el interior se localizó una tumba saíta de planta muy sencilla (número 6). La entrada a la subestructura se realiza mediante un pozo de planta casi cuadrada, construido con sillares de piedra caliza. El final conduce, hacia el norte, a una sala con techo de bóveda de cañón. El estado de conservación es bastante deficiente.

En la actualidad, de la pared este se conservan $8,50 \mathrm{~m}$ y de la pared oeste $2,50 \mathrm{~m}$. La planta es rectangular, no se puede observar el pavimento por la gran presencia de arena, pero durante las excavaciones del Consejo Supremo de Antigüedades se constató que es de piedra caliza. El techo ya estaba destruido en época faraónica, ya que el equipo de excavación egipcio no encontró vestigios de los sillares que debían de formar parte de la bóveda.

M. Hamza documentó la tumba 7, que está al suroeste de la tumba 1 . Se trata de un conjunto de tres cámaras, construidas con piedra caliza, adosadas una al lado de la otra. Dentro de un recorte hecho en el nivel geológico, se construyeron en un primer momento dos estancias rectangulares de una misma tumba. La pared del fondo era común y a ella se adosaban los muros de cierre y de división de los ámbitos, formados por sillares regulares de piedra caliza. El techo era una bóveda de cañón hoy desaparecida. Posiblemente fue por ahí por donde entraron los ladrones, destruyéndola en el momento del saqueo.

La entrada se encuentra en la parte este, cerrada con tres bloques de piedra caliza. Esta entrada conducía a una sala pavimentada con losas de piedra, de las cuales no queda ninguna. En el muro oeste de esta sala había un nicho para los vasos canopos. Posteriormente se construyó una tercera cámara adosada a las anteriores, formando una misma estructura funeraria. El trabajo constructivo de esta última fase está hecho con menos precisión.

Entre las tumbas 1 al norte y 7 al suroeste, existía, a nuestra llegada el año 1992, una enorme montaña de escombros. Realizamos prospecciones geofísicas en 1996 y en 1998 para constatar si podía localizarse alguna sepultura. Los resultados prometedores de la prospección nos llevaron, durante la campaña del año 1999 , al inicio de la excavación del sector al sur de la tumba número 1. En un primer momento se localizó una necrópolis de época bizantina, con sencillas estructuras funerarias de pozo y otras un poco más complejas, con una pequeña superestructura de adobe.

En el interior de una de estas sepulturas, a $3 \mathrm{~m}$ de profundidad, aparecieron los sillares de piedra caliza de una bóveda. El techo, que estaba roto, cubría la cámara de una tumba de época saíta, que desgraciadamente había sido saqueada. Probablemente constaba de un pozo de acceso, que conducía a un pequeño vestíbulo, donde aparecen dispuestas en cruz una sala principal y dos laterales anexas. Hacia el norte del supuesto pozo de acceso aparecía una nueva cámara, que parecía completar el conjunto y que no conservaba el techo con bóveda.

2. De Meulenaere, 1996: 27. 
La sala mayor, situada al sur, tenía planta rectangular, construida con sillares de piedra caliza muy bien trabajados y en cuyos lados largos (E-W), había dos nichos vacíos para depositar los vasos canopos. La estancia estaba cubierta por una bóveda de cañón y contenía un sarcófago antropomorfo de piedra dura anepigráfico, con las características estilísticas propias de este momento artístico. Desgraciadamente, el interior se saqueó en un momento imposible de precisar y no se ha conservado ningún objeto de su ajuar funerario.

Desde el vestíbulo, al oeste, se construyó una cámara, en cuyo interior se localizó una inhumación sin momificar y, desplazadas en un rincón, los despojos de un cuerpo momificado. Una de las hipótesis que se barajan es que se trate del difunto que se encontraría en el sarcófago de piedra. Finalmente, se excavó la cámara anexa situada al este, en un estado muy precario de conservación. El individuo que la ocupó puede datarse en época bizantina por una moneda que nos sitúa entre los siglos VI y VII d.C.

Finalmente, al iniciar un sondeo al sureste de la necrópolis, se pudo apreciar, en el perfil sur de la cala, un gran recorte practicado en el estrato geológico. En el perfil norte los estratos presentaban una inclinación muy fuerte hacia el centro de la excavación. Esta observación, y la gran cantidad de bloques de grandes dimensiones encontrados removidos, nos llevó a pensar que estábamos delante del estrato de destrucción de una tumba monumental de época saíta.

Por debajo del nivel de destrucción aparecieron, en un estrato removido, una gran cantidad de tapas de sarcófagos saítas. Esta capa revuelta se sitúa por encima del pavimento de la tumba, formado por grandes losas de piedra caliza rectangulares. Se conservan de dos a tres hileras de bloques de los muros este y sur. La estructura se prolonga hacia el norte, hacia el este y ya hemos podido localizar el cierre de la tumba hacia el oeste. Se trata de una sepultura familiar con al menos ocho cámaras.

\section{La construcción de las tumbas}

Del estudio de la necrópolis saíta y el análisis de las características arquitectónicas de las tumbas, se puede deducir cuál era el proceso de su construcción en Oxirrinco. Antes de edificar, se excavaba en el terreno un gran recorte rectangular en dirección E-W dentro del nivel geológico. Éste estaba formado por guijarros y arena procedentes de antiguos terrenos aluviales, probablemente de algún wadi, y en el interior se construía la subestructura de la sepultura. En el sector norte de la Necrópolis Alta se puede observar el gran recorte en la que se edificó la tumba número 1 y que por sus dimensiones estaría destinada a más de una estructura funeraria. Este recorte también se puede observar en las tumbas número 7, 13 y 14 en el sector suroeste de la Necrópolis Alta, así como en la número 6.

Estas sepulturas se rodeaban de un muro de cierre, generalmente de adobe, que suele estar destruido en la actualidad. La tumba constaba de una superestructura, generalmente en forma de capilla para el culto funerario del difunto, realizada con piedra caliza. Casi no se ha conservado ninguna de esta época; por tanto, no podemos concretar la forma que tendría en las tumbas saítas de Oxirrinco. Además de esta razón, la necrópolis se sitúa por debajo de las sepulturas de otras épocas que se construyeron encima, eliminando, sin ninguna duda, la superestructura.

El acceso al interior se realiza mediante un pozo de piedra caliza de planta más o menos cuadrada, con una serie de escalones que permitían el descenso de los obreros. A través de una puerta, que se tapiaba con bloques una 
vez hecho el entierro, se accedía a un distribuidor o a la cámara funeraria propiamente dicha. Un ejemplo conservado de este tipo de acceso lo tenemos en la tumba 7. En las puertas de las dos salas más antiguas (las situadas al norte y la central) se encontraban aún tapiadas y en los bloques que las cerraban había textos pintados de rojo. Estos hacen referencia a la fórmula de las ofrendas y los jeroglíficos flanquean verticalmente el pilar dyed rematado con la corona de Ptah-Sokar-Osiris.

La caliza con la que se hacían los bloques procedía, muy probablemente, de las canteras de Minia $^{3}$, ya que cerca del yacimiento no se observa la presencia de esta piedra con esta calidad. Los módulos arquitectónicos de los sillares tienen medidas muy regulares: $1 \mathrm{~m}$ de largo, entre $0,80 \mathrm{~m}$ y $1 \mathrm{~m}$ de anchura y $1 / 2 \mathrm{~m}$ de altura, unidos con mortero de cal de color rosado. El que las medidas de los bloques de piedra sean tan parecidos en las tumbas saítas de las principales necrópolis de Egipto, ha hecho que éste sea uno de los criterios a la hora de ubicar cronológicamente alguna sepultura que no presenta características arquitectónicas claras.

Las sepulturas se construían con piedra caliza blanca, tallada en bloques de diferentes medidas. Muchos de los hallados en la tumba son trapezoidales, para poder trabarlos mejor a la hora de hacer el aparejo. Algunos sillares se desbastaban en la superficie y otros se debían acabar en el interior mismo, tal como se observa en algunos muros. En este último caso, el acabado de la pared presenta una serie de marcas realizadas con un instrumento para picar, que atraviesan la línea de unión entre sillares y que sólo se podían haber hecho una vez estaban colocados los sillares. Las superficies internas de las paredes presentan diversos tipos de tratamiento, desde la piedra rugosa, tal como llegaba de la cantera, hasta mu- ros completamente lisos o ligeramente repicados para la colocación de pinturas murales.

La subestructura de unas muestra una estructura radial y compleja (tumba 13), pero en otras es muy sencilla, con pozo y con una sola sala (tumba 6) o con cámaras adosadas (tumba 7). Algunas son familiares (como la 1 y 14), sin que

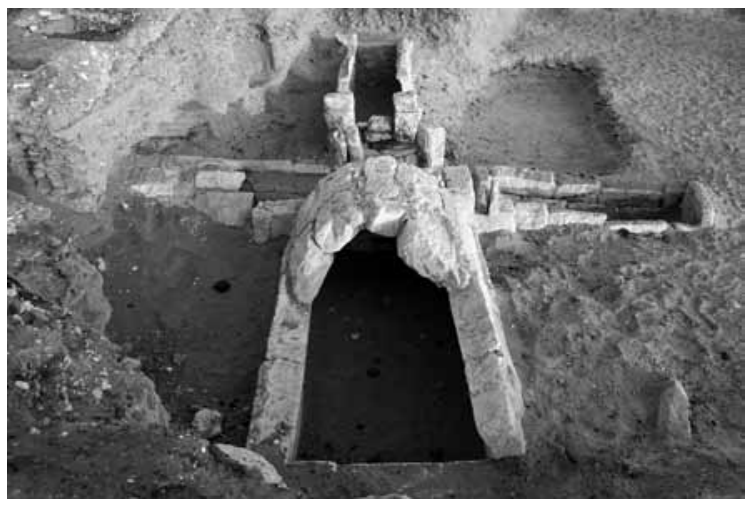

Figura 4. Planta radial de la tumba $n^{\circ} 13$

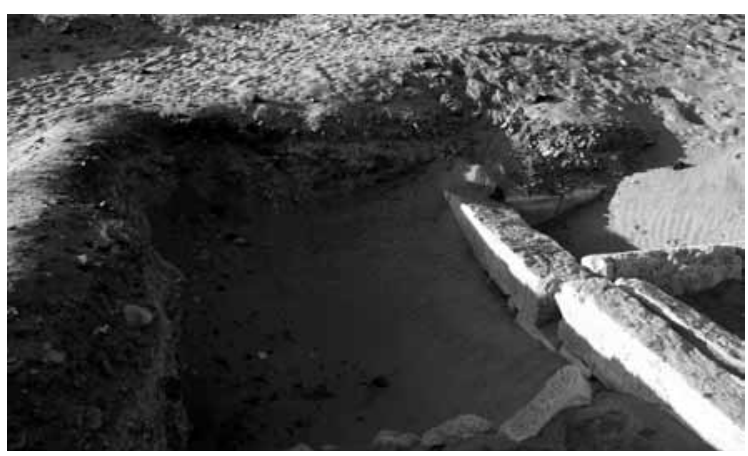

Figura 5. Vista del recorte en el nivel geológico de la tumba $n^{\circ} 7$

conozcamos el parentesco que existe entre los diversos personajes enterrados, ya que la mayoría no muestran ningún tipo de inscripciones. El aprovechamiento de las habitaciones de los diferentes miembros de una familia a partir de un vestíbulo central es un concepto de planificación que también se aplicó a las grandes tumbas de

3. Goyon et alii, 2004: 66-67. 
piedra de la Baja Época. En algunos vestíbulos de estas construcciones funerarias se identifican, gracias a las inscripciones de los dinteles de las puertas, algunas cámaras laterales que se utilizaron como lugar de sepultura de los parientes. Esta idea de construcción de una "sepultura familiar" está en consonancia con el fuerte sentido de familia existente en la época saíta. En Oxirrinco disponemos de dos ejemplos, siendo la número 1 la más conocida. Desgraciadamente, la ausencia de textos no nos ha permitido conocer el parentesco entre los diferentes personajes que fueron allí inhumados. Pero sí que disponemos de una inscripción en el dintel de la puerta que comunica la sala 1 con la 5 . Se trata de un grafito negro en jeroglífico con el nombre de Uahibre, que resulta ser el ocupante de uno de los sarcófagos de la sala 7.

Las primeras hiladas del muro (generalmente son dos) presentan en las esquinas bloques que están preparados para poder sostener el peso de los muros y el techo abovedado. Estos sillares no son completamente rectos, sino que se curvan un poco para poder hacer el ángulo de la esquina. El resto de hiladas se iban modificando en función de la curvatura de la bóveda.

Los suelos de las diferentes cámaras están pavimentados con losas de piedra caliza. Aunque en muchas de éstas el suelo quedó arrasado, en algunas de las salas se puede observar la banqueta de cimentación que da la vuelta a la estancia y en el interior está el espacio para la colocación de las losas horizontales. Los sarcófagos se depositaban por encima del pavimento, con excepción de algunos de ellos como el de Het, promotor de la construcción de la tumba número 1. Para su entierro, se excavó una fosa en el suelo, con los nichos al lado, y se depositó el sarcófago antropomorfo sin caja. La cubierta de las cámaras es una bóveda de cañón, de arco peraltado, cons- truida probablemente con una cintra de madera ${ }^{4}$. A un metro de altura se inicia la cubierta de la sala con una luz que tiene unos $2 \mathrm{~m}$ de media.

En referencia a la decoración de la cripta del sarcófago, la tumba número 1 de Oxirrinco presenta el techo decorado con motivos nocturnos: el cielo estrellado, con estrellas de color amarillo de cinco puntas. Las paredes de la cámara funeraria están decoradas con fórmulas religiosas del Libro de los Muertos, nombre y títulos del difunto y la fórmula de las ofrendas.

La tipología arquitectónica y las medidas de los sillares nos permiten establecer un paralelismo razonable entre las tumbas de Oxirrinco y las de la necrópolis saíta de Heliópolis, que pertenecen al tipo llamado pit-tomb. La característica principal de estas sepulturas es el acceso a la subestructura mediante un pozo estrecho y profundo con escalones en las paredes para los trabajadores, que se conecta al final con una o más cámaras mediante un pasillo corto. La sala construida alrededor del sarcófago, estaba formada por bloques de piedra caliza decorados con textos y dibujos.

\section{El Osireion de Oxirrinco}

Para finalizar, durante toda la Baja Época, el culto al dios funerario Osiris toma mucha importancia. Sus templos en Abidos y Karnak muestran, en época saíta, toda una serie de edificaciones que certifican la devoción popular. Este tipo de construcciones se conoce con el nombre de Osireion o tumba de Osiris, que proliferan en este período y de los cuales el de Abidos es el cenotafio más famoso. Su estructura arquitectónica y simbólica servirá como modelo a las tumbas, especialmente a las de la necrópolis de Assasif en Tebas ${ }^{5}$. En Oxirrinco, los textos de la cámara del sarcófago de Het

4. Aufrère y Golvin, 1997: III, 210-211. 


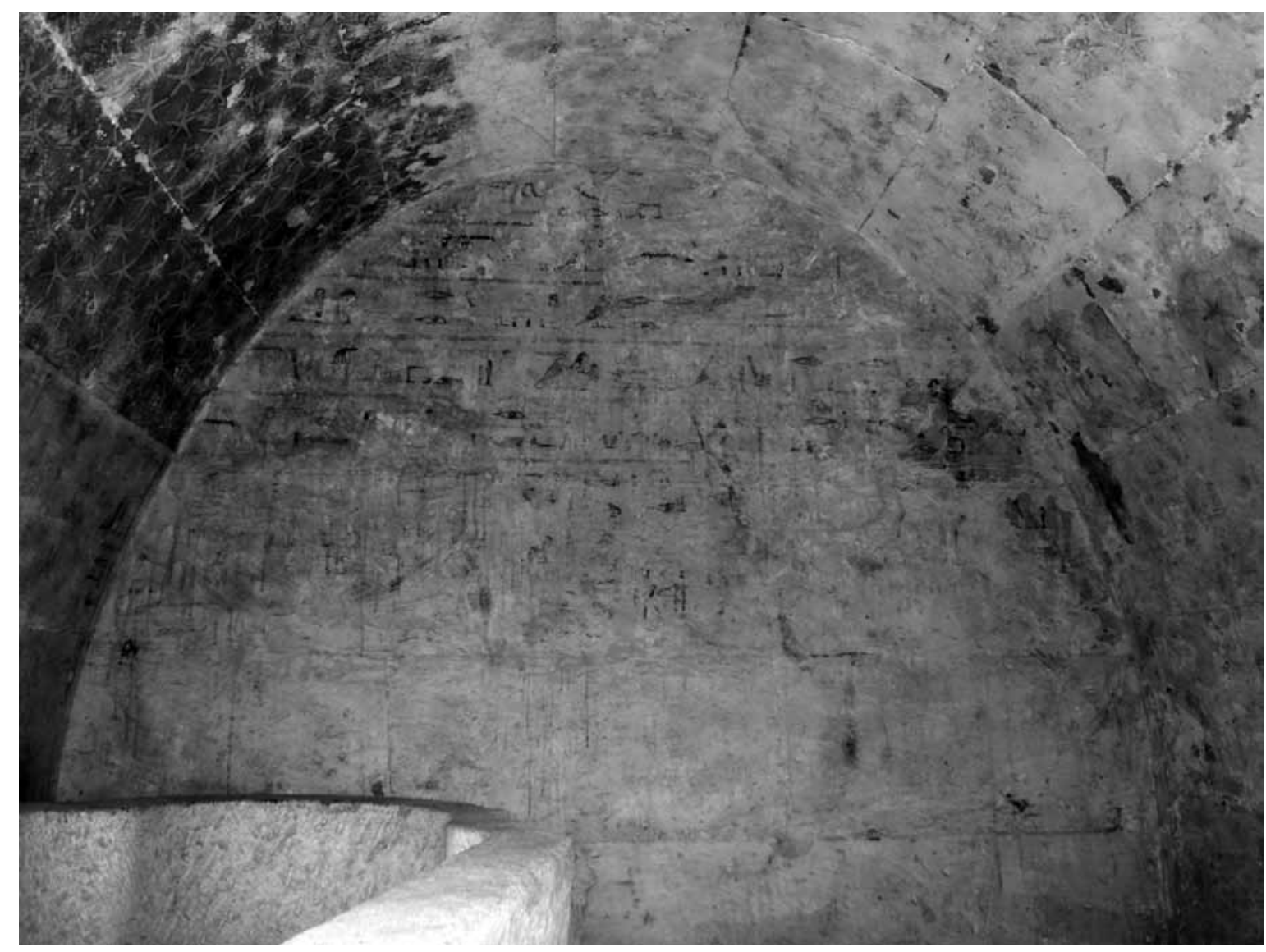

Figura 6. Decoración e inscripciones en la sala 3 de la tumba $n^{\circ} 1$

nos proporcionan información sobre este fenómeno. De hecho, hacen referencia a los títulos del promotor de la sepultura, entre los que destaca el de profeta de Tueris y de Bastis que reside en el ith, heraldo de los dioses de PerMedyed y profeta de los santuarios divinos y de Bastis del $\operatorname{Pr}$ - hf. Este $\operatorname{Pr}$ - hf se ha identificado en Oxirrinco como un templo dedicado a Osiris y por tanto, nos permite afirmar que en este em- plazamiento ya existía en época saíta un Osireion. Aunque los vestigios exhumados hasta el momento se remontan al período ptolemaico, no se descarta que en el interior pueda haber otras galerías más antiguas, o que se pueda localizar otro Osireion más antiguo. En este caso, su descubrimiento nos llevará a esclarecer las relaciones entre el Osireion y las tumbas saítas de la necrópolis de Oxirrinco.

5. Thomas, 1981: 90-92. 


\section{Bibliografía}

Aufrère, S.; Golvin, J.-Cl.

1997 L'Égypte restituée. Tome III: Sites, temples et pyramides de Moyenne et Basse Égypte. Paris.

Bickel, S.; TAllet, P.

1997 La nécropole saïte d'Héliopolis. Étude préliminaire, BIFAO 97: 67-90.

Castellano, $\mathrm{N}$.

2007 The Saite Tomb Number 1 at Oxyrhynkhos and its Parallels, en Goyon, J.-Cl.; Cardin, C. (ed): Proceedings of the Ninth International Congress of Egyptologists. Actes du Neuvième Congrés International des Égyptologues. Grenoble 2004, Lovaina: I, 283-291.

Goyon, J.Cl.; Golvin, J.Cl.; Simon-Boidot, Cl.; Martinet, G.

2004 La construction pharaonique du Moyen Empire à l'époque gréco-romaine. Contexte et principes technologiques. Paris.
MeulenAere, H. DE

1996 Le surnom égyptien à la Basse Époque. Istanbul.

PADRÓ, J.

2003 Le site d'Oxyrhynchos: rapport sur les travaux archéologiques menés depuis 1992, Cadmo 13: 9-25.

Padró, J.; HAmZa, M.; Amer, H.; Mascort,

T.; Subías, E.; Castellano, N.; Morfin, M.;

XARrié, R.

2004 Darreres intervencions al jaciment d'Oxirrinc (El-Bahnasa, Egipte), Tribuna d'Arqueologia 2000-2001: 331-350.

El-Sawi, A.; GomaA, F.

1993 Das Grab des Panehsi, Gottesvaters von Heliopolis in Matariya. (̈̈AT 23). Wiesbaden.

THOMAs, N.

1981 A typological study of Saite tombs at Thebes. (DissAb 8). Michigan. 


\section{Trabajos de Egiptología Papers on Ancient Egypt}

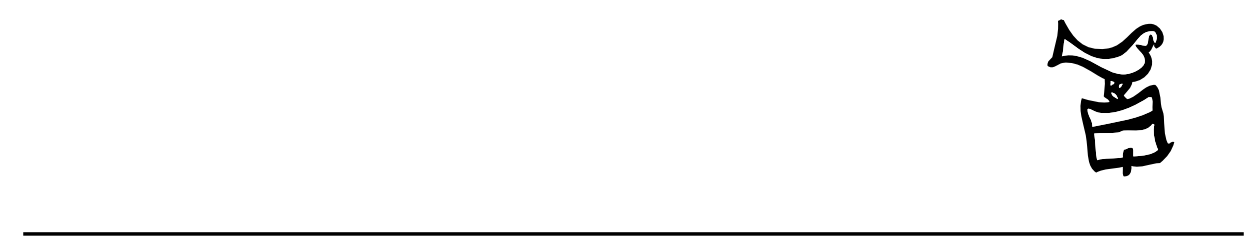

Número 5/1 2009 


\section{Actas \\ III Congreso Ibérico de Egiptología III Congresso Ibérico de Egiptologia}

Editores

Miguel Ángel Molinero Polo Covadonga Sevilla Cueva 


\title{
Editor
}

Miguel Ángel Molinero Polo

Universidad de La Laguna

\section{Consejo Editorial}

\author{
Antonio Pérez Largacha \\ Universidad de Castilla-La Mancha \\ José-R. Pérez-Accino \\ Birkbeck, Universidad de Londres \\ Covadonga Sevilla Cueva \\ Universidad Autónoma de Madrid
}

\section{Comité Científico}

Josep Cervelló i Autuori

Universitat Autònoma de Barcelona

$\mathrm{M}^{\mathrm{a}}$ José lópez Grande

Universidad Autónoma de Madrid

Josep Padró i Parcerisa

Universitat de Barcelona

$\mathrm{M}^{\mathrm{a}}$ Carmen Pérez Die

Museo Arqueológico Nacional, Madrid

Ester Pons Mellado

Museo Arqueológico Nacional, Madrid

José M. Serrano Delgado

Universidad de Sevilla

\section{Colaboradores Editoriales}

Linda Steynor

English editorial assistant

Hervé Mouriacoux

Assistant éditorial pour la langue française 
Trabajos de Egiptología está producida por Isfet. Egiptología e Historia c/ Blanco $1,2^{\circ}$

38400 Puerto de la Cruz

Tenerife-Islas Canarias

España

Maquetación: Proyecto Limón

(C) Autores de los artículos aparecidos

y Consejo Editorial de Trabajos de Egiptología - Papers on ancient Egypt

Depósito Legal: TF-2302-2009

ISSN: $1695-4750$

Imprime: Gráfica Los Majuelos, S.L.L.

imprenta@graficaslosmajuelos.com

Tfno.: 922311455 


\section{Comité Científico \\ III Congreso Ibérico de Egiptología III Congresso Ibérico de Egiptologia}

Miguel Á. Molinero Polo

Universidad de La Laguna

Presidente del Comité Organizador del III Congreso Ibérico de Egiptología

Miembro del Comité Organizador del I Encuentro de Egiptología

Josep Cervelló Autuori

Universitat Autònoma de Barcelona

Presidente del Comité Organizador del II Congreso Ibérico de Egiptologia

José Manuel Galán Allué

Consejo Superior de Investigaciones Cientificas

Director del Proyecto Djehuty, Luxor, Egipto

$\mathrm{M}^{\mathrm{a}}$ Helena Trindade Lopes

Universidad de Lisboa

Directora de la Misión Arqueológica Portuguesa en Menfis

Josep Padró i Parcerisa

Universitat de Barcelona

Director de la Misión Arqueológica de Oxirrinco

Antonio Pérez Largacha

Universidad de Castilla - La Mancha

Miembro del Comité Organizador del I Encuentro de Egiptología

José Ramón Pérez-Accino

Birkbeck College, University of London

Miembro del Comité Organizador del I Encuentro de Egiptología

$\mathrm{M}^{\mathrm{a}}$. Carmen Pérez Díe

Museo Arqueológico Nacional

Directora de la Misión Arqueológica Española en Heracleópolis Magna, Egipto

Covadonga Sevilla Cueva

Universidad Autónoma de Madrid

Miembro del Comité Organizador del I Encuentro de Egiptología 